\title{
Growth and Photosynthesis of Magnolia grandiflora 'St. Mary' in Response to Constant and Increased Container Volume
}

\author{
Chris A. Martini, Dewayne L. Ingram ${ }^{2}$, and Terril A. Ne11 ${ }^{3}$ \\ Department of Environmental Horticulture, IFAS, University of Florida, Gainesville, FL 32611
}

\begin{abstract}
Additional index words. temperature, heat stress, nursery production
Abstract. Growth of Magnolia grandiflora Hort. 'St. Mary' (southern magnolia) trees in containers spaced $120 \mathrm{~cm}$ on center was studied for 2 years. During the 1st year, trees were grown in container volumes of 10, 27, or 57 liter. At the start of the second growing season, trees were transplanted according to six container shifting treatments [10liter containers (LC) both years, 10 to $27 \mathrm{LC}, 10$ to 57LC, 27LC both years, 27 to 57LC, or 57LC both years]. The mean maximum temperature at the center location was 4.8 and $6.3 \mathrm{C}$ lower for the 57LC than for the 27 and $10 \mathrm{LC}$, respectively. Height and caliper, measured at the end of 2 years, were" greatest for magnolias grown continuously in 27 or 57LC. Caliper was greater for trees shifted from 10LC to the larger containers compared with trees grown in $10 \mathrm{LC}$ both years. Trees grown in 10LC both years tended to have fewer roots growing in tbe outer $4 \mathrm{~cm}$ of the growing medium at the eastern, southern, and western exposures. During June and August of the 2nd year, high air and growth medium temperatures may have been limiting factors to carbon assimilation. Maintenance of adequate carbon assimilation fluxes and tree growth, when container walls are exposed to solar radiation, may require increasing the container volume. This procedure may be more important when daily maximum air temperatures are lower during late spring or early fall than in midsummer, because low solar angles insolate part of the container surface.
\end{abstract}

In the first stages of ornamental plant production, young plants are typically transplanted into small containers and spaced container-to-container. This increases plant density per unit land area while minimizing the exposure of container walls to solar radiation. However, growing trees at high density can reduce trunk caliper growth and cause development of a weak branch structure and poor form after canopies converge and overlap (Appleton and Whitcomb, 1983). Shading by converging canopies may encourage leaf abscission and lower branch dieback. Due to the lack of trunk strength from close-production spacing, trees transplanted into the landscape often require remedial staking for support. Enhancement of tree quality, structure, and form may require spacing individual containers at greater distances.

The volume of growth medium in which a plant is grown has been shown to affect carbon partitioning and growth of selected species (Biran and Eliassaf, 1980; Gilliam et al., 1984; Keever et al., 1985). Shoot and root dry weight, leaf area, and stem caliper of bean plants (Phaseolus vulgaris L.) were reduced as container volume was restricted and the partial removal of bean roots decreased carbon assimilation and export of carbon to the roots (Carmi and Keller, 1978; Carmi et al., 1983). The shoot : root ratios of cucumber plants (Cucumis sativus L.) were unchanged as container volume was decreased (Robbins and Pharr, 1988). Robbins and Pharr (1988) postulated that the coordination of shoot and root growth in cucumber plants may have caused an increase in shoot starch content when container volume was restricted.

Several controlled studies have examined high root or air temperature-induced declines in leaf carbon assimilation and

Received for publication 12 Apr. 1990. Florida Agr. Expt. Sta. J. Ser. no. R-00586. The cost of publishing this paper was defrayed in part by the payment of page charges. Under postal regulations, this paper therefore must be hereby marked advertisement solely to indicate this fact.

'Graduate research assistant. Current address: Dept. of Botany, Arizona State Univ., Tempe, AZ 85287.

'Professor. Current address: Dept. of Horticulture and Landscape Architecture, Univ. of Kentucky, Lexington, KY 40546.

${ }^{3}$ Professor. stomatal conductance (Bar-Tsur et al., 1985; Bauer, 1978; Bunce, 1985; Lorenzo-Minguez et al,, 1985; Tenhunen et al., 1984). However, partitioning the environmental factors responsible for changes in leaf photosynthetic fluxes under field conditions is difficult. Fluctuations in the environment have been shown to affect root sink strength (Aung, 1974). Root growth of Pseudotsuga menziesii (Mirb.) Franco after field transplanting was composed primarily of current photosynthate (van den Dreissche, 1987). Container walls intercepting solar radiation may change growth patterns by increasing container medium temperatures. High root-zone temperatures in growth media adjacent to the media-container interface have been correlated with insolation on east-, south-, and west-facing container walls (Martin and Ingram, 1988). Leaf photosynthetic fluxes of Pittosporum tobira were reduced after a 7-month exposure to $40 \mathrm{C}$ for $6 \mathrm{~h}$ daily compared with 27 and 35C (Johnson and Ingram, 1984).

The rate of diffusion of thermal energy in a growth medium is a function of individual constituents. In preliminary research, the thermal diffusivity of a pine bark-based medium ranged from 1.5 to $3.0 \mathrm{E}-07 \mathrm{~m} \cdot \mathrm{s}^{-1}$ and changed relatively little between $30 \%$ and 50\% volumetric water contents (Martin, 1990). By using growth media with similar physical properties and changing only container volume, the center location in a larger container volume may be expected to warm and cool more slowly than that in a smaller container volume while reaching a lower maximum daily temperature. Thus, it may be possible to reduce the exposure of a container-grown root system to high temperatures by use of relatively large containers throughout the container production cycle or by shifting trees to larger container volumes earlier than is usually practiced. The objectives of this research were to investigate the growth and photosynthesis of southern magnolia as affected by container volume that remained constant or was increased, and to correlate physiological variables with container volume and temperature when container walls are exposed to solar radiation.

Abbreviations: A, leaf carbon assimilation; $\mathrm{Ci}$, intercellular $\mathrm{CO}$,; gs, stomata] conductance; LC, liter containers; TA, temperature at canopy height; TC, temperature at center location; TI, time of day; VO, container volume. 


\section{Materials and Methods}

A 2-year study was conducted in Gainesville, Fla. (29.4N, $82.2 \mathrm{~W}$ ), to assess growth and photosynthesis of southern magnolia as affected by three container volumes and six changes in container size (shifting treatments). Softwood stem-cuttings were harvested during Summer 1987 and rooted in 100\% perlite under intermittent mist for 12 weeks. Rooted cuttings were then potted into $25.0-\times 7.5-\mathrm{cm}$ polyethylene sleeves containing MetroMix 500 (Grace-Sierra, Cambridge, Mass.) and overwintered in a gIass-covered greenhouse (37C day maximum/17C night minimum) under natural daylength supplemented with $4 \mathrm{~h}$ of incandescent lighting during the night.

On 1 Mar. 1988, magnolias were transplanted into 10, 27, or 57LC filled with 3 pine bark : 1 peat : 1 sand (by volume) growth medium amended with $\left(\mathrm{kg} \cdot \mathrm{m}^{-3}\right) 5.9$ Osmocote $18 \mathrm{~N}$ 2.6P-9.9K (Grace: Sierra, Milpitas, Calif.), 3.0 dolomite, and 0.9 Micromax (Grace-Sierra, Milpitas). These container volumes correspond to top and bottom widths and depths of 23.5 $\times 23.0 \times 23.0 \mathrm{~cm}, 32.5 \times 31.5 \times 33.0 \mathrm{~cm}$, and $42.5 \times$ $41.5 \times 41.0 \mathrm{~cm}$, respectively. The containers were placed on black polypropylene fabric and the trees were equally spaced $120 \mathrm{~cm}$ on center. Trees were spaced container-to-container from Dec. 1988 through Feb. 1989 for cold protection during the winter. Osmocote fertilizer was also top-dressed on 1 July 1988 and 1989. Application rates were based on container volume and equaled 14,28 , and $42 \mathrm{~g}$ per 10,27 , and $57 \mathrm{LC}$, respectively. Osmocote was top-dressed at one-half the previous rates on 1 Nov. 1988.

"A drip tube irrigation system was installed with one, two, or three drip tubes per 10-, 27-, or 57LC, respectively. Trees were irrigated to container capacity every other day from Mar. to Nov. 1988, and Mar. to Oct. 1989. Water replacement was based on container volume and was applied for $45 \mathrm{~min}$ at an average rate of $12 \mathrm{ml} \cdot \mathrm{min}^{-1}$ per liter of container volume. The replacement of water every 2 days eliminated the possibility of differential, container-medium water potential.

Growth medium temperatures for four replicate containers were recorded for $24 \mathrm{~h}$ once a month during the growing seasons of both years. Copper-constantan thermocouples were positioned in the growth medium half-way down the container profile at the center location and on the east and west coordinates, $2 \mathrm{~cm}$ inside the container wall. The thermocouples were connected to a $21 \times$ micrologger with AM-32 multiplexer (Campbell Scientific, Logan, Utah). Air temperature was recorded 1.3 $\mathrm{m}$ above ground (average tree canopy height) by a thermocouple shaded from direct solar radiation. All temperature data were recorded every 5 min and averaged over each 15 -min interval.

Tree height and caliper were measured monthly between 1 Mar. and 1 Nov. 1988, and between 1 Mar. and 1 Oct. 1989. Height was determined from the crown of each tree to the base of the highest apical bud. Caliper was measured with a Digimatic caliper (Mitutoyo Corp., Japan). Height and caliper derivatives (din) were calculated for the 1st year as the difference between a measurement $\left(\mathrm{m}_{\mathrm{x}}\right)$ and the initial measurement $\left(\mathrm{m}_{\mathrm{i}}\right)$, using $\mathrm{dm}=\left(\mathrm{m}_{\mathrm{x}}-\mathrm{m}_{\mathrm{i}}\right)$.

On 1 Mar. 1989, six trees (two replications) per container volume were harvested to determine root dry weight. Roots were severed from the shoots at the soil line. The root system was then partitioned into five sections according to location in the growth medium cylinder. A 4-cm-thick layer around the outside wall of the entire growth medium cylinder was separated from the remaining growth medium core. This outside layer was then divided into four sections corresponding to the east, south, west, and north coordinates. Roots in each of the four sections and the growth medium core were washed with a high-pressure nozzle and oven-dried at $70 \mathrm{C}$ for $48 \mathrm{~h}$ before dry weights were determined. The remaining unharvested trees were transplanted according to six shifting regimens of 1) 10 to $10 \mathrm{LC}, 2) 10$ to 27LC, 3) 10 to $57 \mathrm{LC}$, 4) 27 to $27 \mathrm{LC}, 5) 27$ to $57 \mathrm{LC}$, or 6) 57 to 57LC and grown for a second growing season. On 1 Ott. 1989 , the experiment was terminated and roots were severed from shoots and sectioned as described above except that an additional layer was made by separating the bottom $2.5 \mathrm{~cm}$ of the growth medium from the remaining four sections and growth medium core. This procedural change was made after observing variation in the numbers of roots growing at the growth medium bottom. Harvested roots were washed, oven-dried, and dry weights were determined.

Diurnal, measurements of leaf carbon assimilation (A), stomatal conductance $(\mathrm{gs})$, and intercellular $\mathrm{CO}_{2}(\mathrm{Ci})$ were made at monthly intervals during May to Sept. 1989 on nine trees per container volume, using a portable photosynthesis system containing a LI-6200 computer and LI-6250 gas analyzer (LI-COR, Lincoln, Neb.). A diurnal measurement event consisted of measurements during the morning from 0830 to $1000 \mathrm{HR}$, at midday from 1230 to $1400 \mathrm{HR}$, and during late afternoon from 1630 to $1800 \mathrm{HR}$. On 24 Aug. 1989, PPF values were $961 \pm 143$,2088 \pm 75 , and $1375 \pm 127 \mu \mathrm{mol} \cdot \mathrm{s}^{-1} \cdot \mathrm{m}^{-2}$ for morning, midday, and late afternoon measurement periods, respectively. The same nine trees per treatment were selected on each measurement date and readings were made on the most recently matured leaf, which was typically two to five leaves from the shoot apex. A 0.25 -liter cuvette chamber was used for measurements and the mean of three consecutive observations of at least a $5 \mu \mathrm{CO}_{2}$ drawdown on each leaf comprised an experimental unit. Magnolia leaf area for the cuvette chamber surface was $17.5 \mathrm{~cm}^{2}$ for each measurement. Measurement cycles were scheduled for days when fair weather was anticipated.

The experiment was arranged in a completely randomized design with five treatment replications and three tree samples per replication. General linear models procedures were used to test for significant responses of the variables. Regression coefficients were tested for homogeneity of fit using the $F$ test. Repeated measures analysis was used to compare temporal changes in growth as affected by treatments. Probabilities for the $\mathrm{F}$ test for time and time $\times$ treatment interactions for height and caliper were made using the Greenhouse-Geiser adjustment to univariate $P$ values (Littel, 1989). Height and caliper data were analzyed by container volume and shifting regimes for the 1 st and 2nd years, respectively. Leaf A, gs, and Ci were analyzed by container volume and time of day.

\section{Results and Discussion}

Average container medium temperatures for a typical, mostly sunny, summer day in Florida illustrate the effect of container volume on temperature patterns at the center location in the pot (Fig. 1). The air maximum was $41 \mathrm{C}$ (1630 HR) at canopy height. The mean maximum temperature at the center location of the 57,27 , and $10 \mathrm{LC}$ was $36.0 \pm 2 . \mathrm{OC}(1930 \mathrm{HR}), 40.8 \pm 1.1 \mathrm{C}$ $(1730 \mathrm{HR})$, and $42.3 \pm 1.5 \mathrm{C}(1845 \mathrm{HR})$, respectively. The highest mean growth medium temperature occurred at the western exposure for all container sizes and was $45.3 \pm 2.2 \mathrm{C}$ (1630 HR), $45.4 \pm 1.4 \mathrm{C}(1715 \mathrm{HR})$, and $48.1 \pm 2.3 \mathrm{C}(1745 \mathrm{HR})$ for the 57,27 , and $10 \mathrm{LC}$, respectively. The mean temperature at the center location and eastern exposure of the 10LC exceeded 


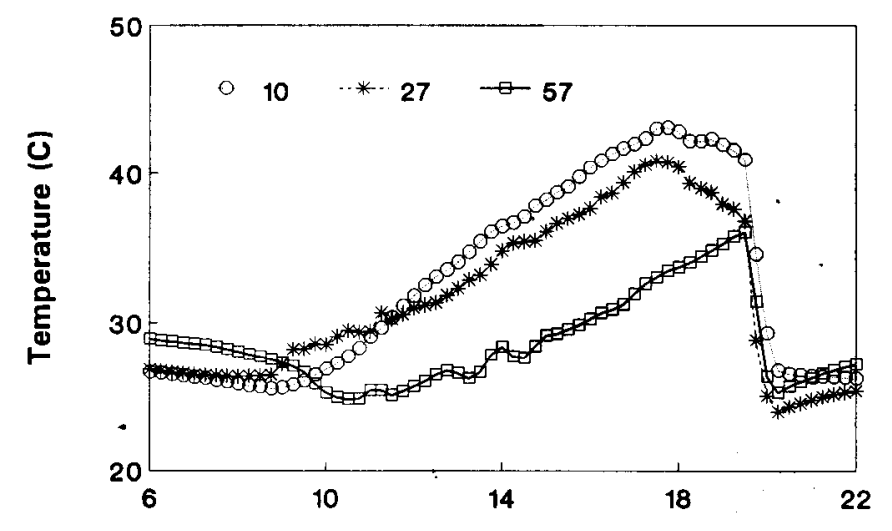

Time (EDS)

Fig. 1. Growth medium temperatures (C) at the center location for 10, 27, and 57LC, 24 Aug. 1989. Rapid decrease at 1915 HR due to thunderstorm. Temperatures are treatment means, $n=4$.

Table 1. Analysis of variance of significant polynomial time trends and treatment contrasts for height and trunk caliper of Magnolia grandiflora 'St. Mary' during 1988 and 1989.

\begin{tabular}{|c|c|c|c|c|}
\hline Source of variation & $\mathrm{df}$ & MS & $\mathrm{F}$ & $P>$ F value \\
\hline \multicolumn{5}{|l|}{1988 ht derivatives ${ }^{y}$} \\
\hline Time & 1 & 31.56 & 6.20 & $0.001 \mathrm{Q}$ \\
\hline 10 vs. 27 and 57 & 1 & 2711.17 & 17.75 & $0.001 \mathrm{~L}$ \\
\hline 27 vs. 57 & 1 & 147.05 & 7.36 & $0.005 \mathrm{~L}$ \\
\hline \multicolumn{5}{|l|}{1988 caliper derivatives } \\
\hline Time & 1 & 44.31 & 8.70 & $0.004 \mathrm{~L}$ \\
\hline 10 vs. 27 and 57 & 1 & 64.42 & 13.23 & $0.005 \mathrm{~L}$ \\
\hline \multicolumn{5}{|l|}{1989 height increases ${ }^{x}$} \\
\hline Time & 1 & 55.57 & 2.59 & $0.034 \mathrm{~L}$ \\
\hline A vs. $B$ and $C$ & 1 & 2175.85 & 16.56 & $0.001 \mathrm{~L}$ \\
\hline E vs. $D$ and $F$ & 1 & 1247.14 & 9.49 & $0.003 \mathrm{~L}$ \\
\hline $\mathrm{A}, \mathrm{B}$, and $\mathrm{C}$ vs. $\mathrm{D}, \mathrm{E}$, and $\mathrm{F}$ & 1 & 9877.93 & 75.20 & $0.001 \mathrm{~L}$ \\
\hline \multicolumn{5}{|c|}{1989 Caliper increases } \\
\hline Time & 1 & 199.39 & 17.45 & $0.001 \mathrm{~L}$ \\
\hline A vs. $B$ & 1 & 46.84 & 4.10 & $0.047 \mathrm{~L}$ \\
\hline A vs. $\mathrm{C}$ & 1 & 139.49 & 12.21 & $0.009 \mathrm{~L}$ \\
\hline$A, B$, and $C$ vs. $D, E$, and $F$ & 1 & 896.41 & 78.47 & $0.001 \mathrm{~L}$ \\
\hline
\end{tabular}

${ }^{2} \mathrm{~L}$ and $\mathrm{Q}$ represent linear and quadratic responses over time, respectively.

${ }^{y}$ For 1988 height and caliper, trees were grown in 10-, 27-, or 57-liter containers, respectively.

${ }^{x}$ For 1989 height and caliper, A, B, C, D, E, and F are shifting regimes indicating container volumes used the 1 st and 2 nd years and are as follows: A“", 10 liter both years, B, 10 to 27 liter, C, 10 to 57 liter, D, 27 liter both years, E, 27 to 57 liter, and F, 57 liter both years.

40C from 1515 to 1915 HR and from 1015 to 1915 HR, respectively, on this day.

Growth analysis. Height growth of southern magnolia increased quadratically over time during the 1st year; however, the rate of increase for trees grown in 27 and 57LC was greater than for trees in 10LC (Table 1). At the end of the 1st year, height of trees grown in 10LC was $46 \%$ and $54 \%$ less than that of trees in 27 and 57LC, respectively (Fig. 2). Height differences as a function of container volume became visually apparent during midsummer. The July fertilizer application coincided with an additional growth flush for all treatments during July, which may have caused the large growth increase after this time (Fig. 2). Furthermore, the growth flushes for trees in 27 and 57LC were greater than for those in 10LC. Higher root-zone

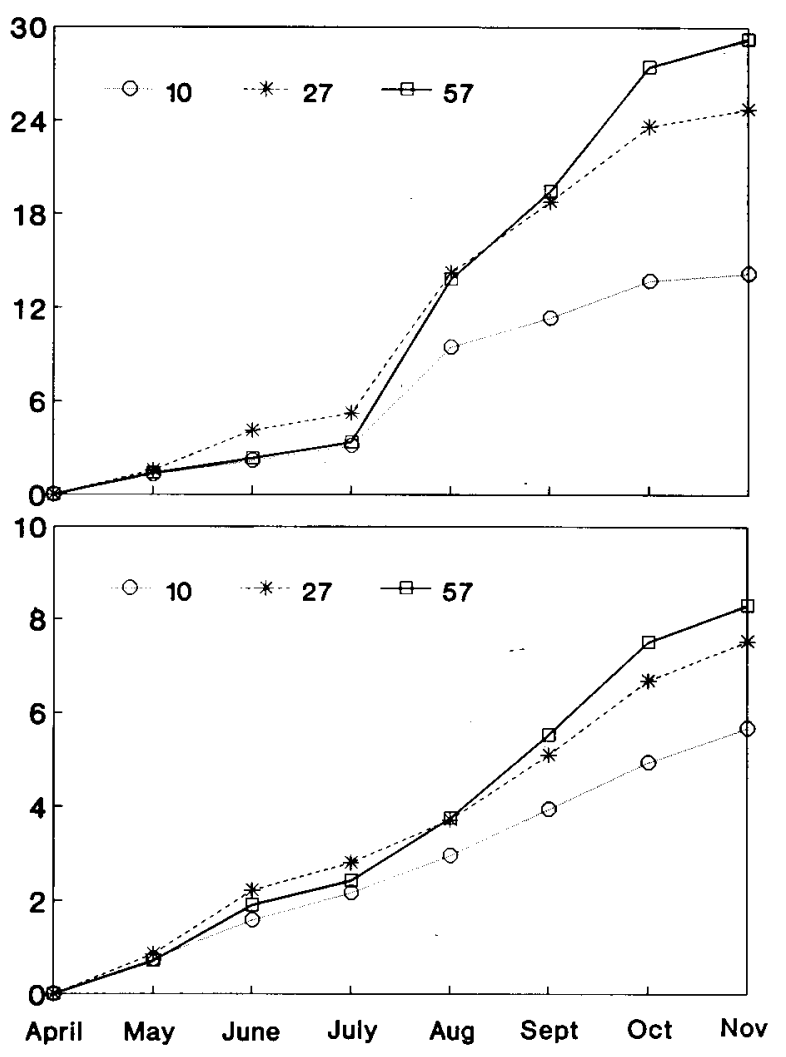

Fig. 2. Cumulative height and caliper derivatives of Magnolia grandiflora 'St. Mary' over time when grown in 10, 27, or 57LC during

1988. Changes in height and caliper are treatment means, $\mathrm{n}=15$.

temperatures in the 10LC compared with the 27 and 57LC may have reduced the capacity of magnolia to take up or translocate essential minerals (Harrison, 1989). Caliper growth of southern magnolia increased linearly over time the 1st year; however, the rate of increase for trees grown in 27 and 57LC was greater than for trees in 10LC (Table 1). At the end of the 1st year, caliper of trees in 57LC was 1.5 times greater than for trees in 10LC (Fig. 2). Similar responses for height and caliper growth of trees grown in large containers were found on 'Bradford' Canary pear (Gilliam et al., 1984) and red maple (Martinet al., 1989).

For the 2nd year, growth was generally greater for trees shifted to larger containers (Fig. 3). Growth flushes for all treatments occurred during April and May (Fig. 3). However, a second growth flush occurred during August and September, particularly for trees grown in 27 and 57LC. Analysis of 2nd-year time trends for height demonstrated that 1) regardless of shifting treatment, the height increase of trees grown in 27 or $57 \mathrm{LC}$ was greater than for trees grown in 10LC the 1st year, 2) the height increase of trees grown both years in 27 or 57LC was greater than for trees transplanted from 27 into 57LC, and 3) the height increase of trees transplanted from 10LC into 27 or 57LC was greater than for trees grown both years in 10LC (Table 1). Analysis of 2nd-year time trends for caliper demonstrated that 1) regardless of shifting treatment, the caliper increase of trees grown in 27 or 57LC during the 1st year was linearly greater than for trees grown in 10LC the 1st year, 2) the caliper increase of trees transplanted from 10LC into 27 or 57LC was greater than for trees grown both years in 10LC (Table 1).

Shoot and root biomass accumulation followed patterns similar to those observed for height and caliper growth. In 1988, 

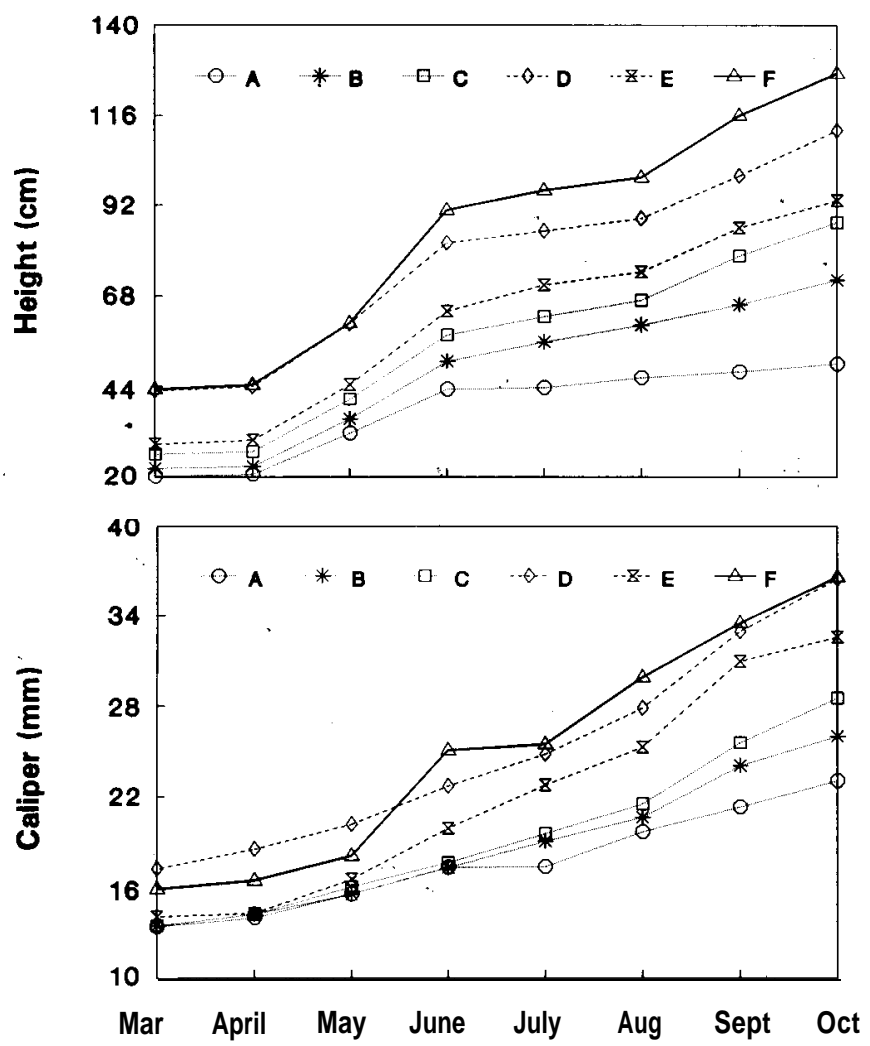

Fig. 3. Height and caliper of Magnolia grandiflora 'St. Mary' over time during 1989 as a function of container volume shifting on 1 Mar. 1989. Shifting treatments indicating container volumes used the 1st and 2nd years are as follows: (A) 10 liter both years, (B) 10 to 27 liter, (C) 10 to 57 liter, (D) 27 liter both years, (E) 27 to 57 liter, and (F) 57 liter both years. Height and caliper are treatment means, $\mathrm{n}=15$.

total root dry weight, root dry weights from the south and west outer layers, and root dry weight from the growth medium core increased linearly with increased container volume (data not shown). Mean total root dry weight ranged from $96 \mathrm{~g}$ in 10LC to $179 \mathrm{~g}$ in $57 \mathrm{LC}\left(P>\mathrm{F}=0.002, r^{2}=0.58, \mathrm{n}=6\right)$. In 1989 , root dry weight in the north, east, south, and west layers and the core of the growth medium was differentially affected by container shifting treatments (Table 2). Root dry weight in the north, east, and south layers was highest for trees grown both years in 57LC. Root dry weight in the west layer was similar for trees grown both years in 27 or 57LC and higher than for those grown in smaller containers. Although the total root dry weight from the north layer of trees grown both years in 10LC was less than for those from the 27 or 57LC, about twice as much of the root mass of trees grown in 10LC was found in the north layer (Table 2). The mass of roots distributed in the growth medium core was reduced in 10LC volumes used the 1st year, although the percentage was equivalent regardless of volume (Table 2). Root dry weight in the bottom layer was highest for trees grown both years in 27 or 57LC. Total root dry weight was greater for trees grown continuously in 27 and $57 \mathrm{LC}$ than in 10LC the 1st year.

Shoot dry weight was highest for magnolias grown both years in 57LC and was higher for trees grown only in 27LC than "those grown in 10LC the 1st year, regardless of container volume the 2 nd year. Shoot dry weight of magnolias transplanted from 10LC into 57LC was higher than for those shifted from $10 \mathrm{LC}$ into $27 \mathrm{LC}$ or grown in 10LC both years.

The shoot : root ratio of trees shifted from 10LC into 57LC after 1 year was similar to that for trees grown in 57LC both years, and was twice that of trees transplanted from 10LC into $27 \mathrm{LC}$ or grown in 10LC both years. A greater portion of the root systems of trees grown in 10LC was exposed to higher root-zone temperatures for a longer period than that in 27 or 57LC (Fig. 1). Root-zone temperatures that reach supraoptimal, yet sublethal, levels have been correlated with increased respiration and carbon leakage in roots of Ilex crenata 'Rotundifolia' (Ruter and Ingram, 1990). The higher root-zone temperatures in 10LC in the present study may have resulted in an expanded root sink for carbon, due to increased respiration and carbon leakage, which would reduce shoot growth for southern magnolias grown in 10LC.

Higher root-zone temperatures in the smaller containers may have further accentuated the differences in biomass accumulation and distribution. During the second growing season, the canopies of trees in the 27 and 57LC partially to completely shaded the container walls from direct solar radiation. However, the unshaded walls of the 10LC were exposed to daily rhythms of solar radiation that created zones inside the container medium profile where growth medium temperatures may have frequently exceeded critical thresholds for maintenance of root membrane integrity (Ingram, 1985; Ingram and Ramcharan, 1988). These zones occur principally in the east, south, and west layers of the growth medium (Martin, 1990). The ramifications of having supraoptimal temperatures in at least a portion of the growth-medium profile may be to 1) restrict the viable volume available for root growth, 2) change the distribution pattern of roots within the container medium profile, and 3 ) reduce overall root and shoot growth. Trees grown in 10LC tended to have a greater percentage of total root system in the north and bottom layers than those in

Table 2. Effect of container shifting regimes on root distribution and total root dry weight, shoot dry weight, and shoot : root ratio of Magnolia grandiflora 'St. Mary' at the end of 2 years, 1989.

\begin{tabular}{|c|c|c|c|c|c|c|c|c|c|c|c|c|c|c|c|}
\hline \multirow{3}{*}{$\begin{array}{l}\text { Vol. of } \\
\text { container and } \\
\text { shifting } \\
\text { treatment (liter) }\end{array}$} & \multicolumn{13}{|c|}{ Root distribution-wt $(\mathrm{g})$ and proportion $(\%)^{2}$} & \multirow{3}{*}{$\begin{array}{l}\text { Shoot } \\
w \underline{t} \\
(\mathrm{~g}) \\
\end{array}$} & \multirow{3}{*}{$\begin{array}{l}\text { Shoot } \\
\text { rogt } \\
\text { ratio }\end{array}$} \\
\hline & \multicolumn{2}{|c|}{ North } & \multicolumn{2}{|c|}{ East } & \multicolumn{2}{|c|}{ South } & \multicolumn{2}{|c|}{ West } & \multicolumn{2}{|c|}{ Core } & \multicolumn{2}{|c|}{ Bottom } & \multirow{2}{*}{$\begin{array}{c}\text { Total } \\
\text { (g) }\end{array}$} & & \\
\hline & $\mathrm{g}$ & $\%$ & $\mathrm{~g}$ & $\%$ & $\mathrm{~g}$ & $\%$ & $\mathrm{~g}$ & $\%$ & g & $\%$ & $\mathrm{~g}$ & $\%$ & & & \\
\hline 10 & $10 \mathrm{~b}$ & 10.3 & $1 \mathrm{c}$ & 1.4 & $2 \mathrm{~d}$ & 1.8 & $1 \mathrm{c}$ & 1.2 & $57 \mathrm{c}$ & 61.4 & $22 \mathrm{~b}$ & 24.0 & $94 \mathrm{~b}$ & $123 \mathrm{~d}$ & $1 \mathrm{c}$ \\
\hline 10 to 27 & $10 \mathrm{~b}$ & 6.0 & $5 \mathrm{c}$ & 2.8 & $3 \mathrm{~cd}$ & 2.9 & $1 \mathrm{c}$ & 0.5 & 125 bc & 74.4 & $24 \mathrm{~b}$ & 14.3 & $168 \mathrm{~b}$ & $223 \mathrm{~d}$ & $1 \mathrm{bc}$ \\
\hline 10 to 57 & $15 \mathrm{~b}$ & 7.7 & $4 \mathrm{c}$ & 2.0 & $1 \mathrm{~d}$ & 0.7 & $4 \mathrm{bc}$ & 2.1 & $144 \mathrm{~b}$ & 75.0 & $24 \mathrm{~b}$ & 12.0 & $192 \mathrm{~b}$ & $347 \mathrm{c}$ & $2 a$ \\
\hline 27 & $19 \mathrm{~b}$ & 5.0 & $14 \mathrm{~b}$ & 4.1 & $10 \mathrm{~b}$ & 2.7 & $13 \mathrm{ab}$ & 3.6 & $248 \mathrm{a}$ & 66.6 & $69 \mathrm{a}$ & 18.6 & 373 a & $575 \mathrm{~b}$ & $2 a b c$ \\
\hline 27 to 57 & $19 \mathrm{~b}$ & 5.0 & $12 \mathrm{~b}$ & 3.1 & $8 \mathrm{cb}$ & 2.2 & $8 \mathrm{bc}$ & 2.1 & $290 \mathrm{a}$ & 77.3 & $38 \mathrm{~b}$ & 10.1 & $375 \mathrm{a}$ & $559 \mathrm{~b}$ & $2 \mathrm{abc}$ \\
\hline 57 & 32 a & 7.1 & $21 \mathrm{a}$ & 4.7 & $18 \mathrm{a}$ & 4.0 & $20 \mathrm{a}$ & 4.4 & $304 \mathrm{a}$ & 68.4 & $72 \mathrm{a}$ & 16.2 & $445 \mathrm{a}$ & 841 a & $2 \mathrm{ab}$ \\
\hline
\end{tabular}

${ }^{7}$ Mean separation within columns by Duncan's multiple range test, $P=0.05, \mathrm{n}=9$. 
27 and 57LC, suggesting that root growth in the east, south, and west zones was inhibited (Table 2).

Photosynthesis. Container volume affected magnolia leaf A when measurements were taken in May, August, and September (Table 3). Leaf A was 200\%, 159\%, and 202\% greater in May, August, and September, respectively, for trees grown in 57LC compared with 10LC. Leaf A in June and August was reduced at midday and late afternoon compared with early morning, and recorded values for gs and $\mathrm{Ci}$ were consistently lower at midday and late afternoon compared with early morning for every measurement date except in May (Tables 3 and 4). For May, gs was increased and $\mathrm{Ci}$ was higher in the early morning and late afternoon compared with midday. Values for $\mathrm{Ci}$ were not affected by container volume (VO) on any date (data not shown). Leaf A was not affected by either VO in June or July or by time of day (TI) in July (Table 3). There were no interactions between VO and TI.

- Different correlative patterns of leaf A and gs to mean recorded growth medium temperature at the center location (TC), VO, TI, and ambient air temperature at canopy height (TA) occurred during Summer 1989 (Fig. 4). Correlations of $r \geq$ 0.50 for leaf A to VO occurred in May, August, and September (Fig. 4). Poor correlations between leaf A and VO in June and July coincided with high maximum TA (41 and 40C at canopy height for June and July, respectively) and slower increases in height (Fig. 3). Correlations of $r$ less than or equal to -0.50 for leaf A to TC, TI, or TA occurred in June, July, and August. Values obtained for gs correlated poorly with VO in every month and negatively with TC, TI, or TA in June, July, August, and September. Reduced gs later in the day in all months except May (Table 3) coincided with times of higher TC even though maximum TA had decreased from $41 \mathrm{C}$ in June to $34 \mathrm{C}$ in September (Table 3). A rainshower in May between the midday and late afternoon measurement periods decreased TC and TA, which may have facilitated increases in $\mathrm{gs}, \mathrm{Ci}$, and leaf $\mathrm{A}$ as a function of TI. After the rainshower, recorded TC in all container sizes was $<35 \mathrm{C}$ and TA was lowered from 39 to $32 \mathrm{C}$.

Under the current production system, magnolia leaf photosynthetic capacity appeared to be influenced by different factors for successive measuring dates. Differences in the correlation of leaf A to VO tended to be inversely related to correlations of leaf A to gs (Fig. 4, and Table 3). For May and September, lower overall growth medium temperatures and a greater capacity for the uptake of essential nutrients due to the larger root systems in the larger container volumes may have partially caused the positive correlation between leaf $\mathrm{A}$ and VO, and suggest that declines in leaf $\mathrm{A}$ in May and September were partially nonstomatal in nature. In June, supraoptimal recorded values for TC and TA may have facilitated declines of leaf A, especially during midday and late afternoon (Tenhunen et al., 1984). In August, a decrease in the incidence of solar radiation intercepted by container walls, due to the increased growth and larger canopies of trees in 27 and 57LC compared with 10LC, may further explain highly positive correlations of leaf A to $\mathrm{VO}$ concurrent with highly negative correlations of leaf A to TC. In June and August, the positive correlation of leaf A to gs in conjunction with a diurnal pattern of lower leaf $\mathrm{A}$, gs, and $\mathrm{Ci}$ during midday and late afternoon compared with morning, suggests that the declines in leaf A were at least partially induced by stomatal closure (Wong et al., 1979). However, this conclusion is not supported by the data for July where leaf A was not affected by $\mathrm{TI}$ even though significant reductions in $\mathrm{gs}$ and lower $\mathrm{Ci}$ as a function of TI had occurred. The photosynthetic measurements taken in July were made on a clear day following several cloudy days accompanied by heavy rainfall. The trees in all container volumes appeared nonstressed. The decrease in gs as a function of TI and the diurnal pattern of lower Ci during midday and late afternoon compared with morning did not appear low enough to cause any significant reductions in leaf $\mathrm{A}$ (Dietz and Heber, 1986; Mott, 1988; Prinsley et al., 1986; Woodrow, 1986).

Consistently, strongly negative correlations of gs with TC and TA in June, July, August, and September also suggest that 1) stomatal aperture is coupled with environmental factors such as temperature, vapor pressure deficits, and soil moisture (Cowan, 1977; Cowan and Troughton, 1971) and 2) a mechanism exists for controlling gs in response to a temperature-induced stress in the roots. A possible mechanism for transmission of a signal from the roots to leaves could involve alterations in the translocation patterns of hormones such as cytokinins or abscisic acid

Table 3. Mean leaf A and gs as a function of VO and TI, and Pearson's correlation coefficient (r) of leaf A to gs for Magnolia grandiflora 'St. Mary'; Summer 1989.

\begin{tabular}{|c|c|c|c|c|c|c|c|c|c|c|}
\hline \multirow[b]{3}{*}{ Treatment $^{2}$} & \multicolumn{10}{|c|}{ Time of measurement } \\
\hline & \multicolumn{2}{|c|}{ May } & \multicolumn{2}{|c|}{ June } & \multicolumn{2}{|c|}{ July } & \multicolumn{2}{|c|}{ August } & \multicolumn{2}{|c|}{ September } \\
\hline & VO & $\mathrm{TI}$ & $\mathrm{VO}$ & TI & $\mathrm{V} \Omega$ & $\mathrm{TI}$ & $\mathrm{VO}$ &. $\mathrm{TI}$ & $\mathrm{VQ}$ & $\mathrm{TI}$ \\
\hline \multicolumn{11}{|c|}{$\begin{array}{l}\text { Leaf A } \\
\qquad\left(\mu \mathrm{mol} \cdot \mathrm{s}^{-1} \cdot \mathrm{m}^{-2}\right)\end{array}$} \\
\hline I & 4.5 & 7.9 & 3.8 & 5.9 & 6.7 & 8.0 & 4.6 & 7.2 & 5.6 & 8.8 \\
\hline II & 6.1 & 5.6 & 4.9 & 3.6 & 8.9 & 8.3 & 6.1 & 5.3 & 9.3 & 9.8 \\
\hline III & 8.9 & 6.4 & 4.5 & 3.8 & 7.4 & 7.0 & 7.8 & 3.9 & 11.3 & 8.1 \\
\hline$P>\mathrm{F}$ & 0.001 & 0.001 & 0.079 & 0.001 & 0.231 & 0.103 & 0.036 & 0.001 & 0.001 & 0.107 \\
\hline$r^{2}$ & 0.70 & & 0.98 & & 0.44 & & 0.89 & & 0.91 & \\
\hline \multicolumn{11}{|c|}{$\mathrm{gs}\left(\mathrm{mmol} \cdot \mathrm{m}^{-2} \cdot \mathrm{s}^{-1}\right)$} \\
\hline I & 1.9 & 2.1 & 1.0 & 1.6 & 2.8 & 4.5 & 1.7 & 3.4 & 2.2 & 3.8 \\
\hline II & 2.1 & 1.7 & 1.1 & 0.9 & 3.1 & 2.2 & 2.3 & 1.6 & 3.0 & 2.2 \\
\hline III & 2.8 & 3.1 & 1.2 & 0.9 & 2.3 & 1.5 & 2.0 & 1.2 & 3.1 & 2.2 \\
\hline$P>\mathrm{F}$ & 0.011 & 0.003 & 0.096 & 0.001 & 0.078 & 0.001 & 0.122 & 0.001 & 0.013 & 0.007 \\
\hline$r^{2}$ & 0.68 & & 0.96 & & 0.91 & & 0.96 & & 0.93 & \\
\hline$r_{\mathrm{A}-\mathrm{gs}}$ & $0.54^{y}$ & & 0.95 & & 0.82 & & 0.72 & & 0.60 & \\
\hline
\end{tabular}

'I, II, and 1111 represent 10-, 27-, and 57-liter container volumes, respectively, for VO and morning, midday, and late afternoon, respectively, for TI.

${ }^{\mathrm{Y}}$ Treatment means, $\mathrm{n}=9$. 


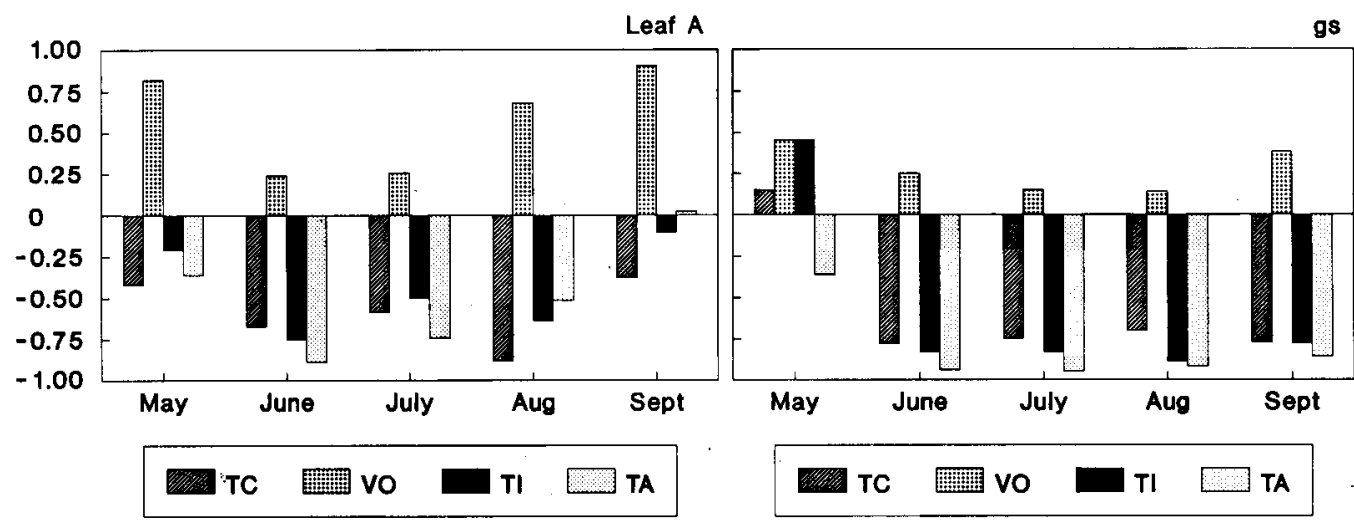

Fig. 4. Pearson's correlation coefficients showing the correlation of A and gs of Magnolia grandiflora 'St. Mary' to mean recorded growth medium TC, VO, TI, and ambient TA during 1989. Correlation coefficient; were calculated from treatment means, $\mathrm{n}=9$.

Table 4. Ci as a function of time of day for Magnolia grandiflora 'St. Mary'; Summer 1989.

\begin{tabular}{lccccc}
\hline \hline & \multicolumn{5}{c}{ Month of measurements } \\
\cline { 2 - 6 } Time of day & May & June & July & August & Setember \\
\hline \multirow{5}{*}{ Morning } & $255.0^{z}$ & 264.9 & 284.4 & 284.6 & 307.6 \\
Midday & 244.2 & 242.1 & 235.3 & 243.6 & 243.1 \\
Late afternoon & 268.7 & 243.3 & 226.5 & 247.3 & 245.7 \\
$P>$ F & 0.001 & 0.002 & 0.001 & 0.001 & 0.001 \\
$r^{2}$ & 0.51 & 0.48 & 0.87 & 0.74 & 0.88 \\
\hline Treatment means, $\mathrm{n}=9$. & \multicolumn{5}{c}{$r$}
\end{tabular}

(Gur et al., 1976). Such a mechanism has been proposed for explaining stomatal responses to high soil salinity and low soil moisture (Bunce, 1988; Downtown et al., 1988; Flanagan and Jefferies, 1988; Zhang et al., 1987).

Our results suggest that using large containers to increase leaf $\mathrm{A}$ and biomass accumulation and shorten the container production phase of southern magnolia, when individual containers are spaced apart, may be most beneficial during periods when the solar declination angle is low and/or TA is $<40 \mathrm{C}$. During the growing season, these meteorological conditions are likely to occur in Florida during the late spring and early fall. A decline in the solar declination angle will increase the surface area of the container wall that is exposed to direct solar radiation (Martin, 1990). This can reduce the potential shading of the container wall by the tree canopy and may result in supraoptimal rootzone temperatures. The use of large containers will reduce the detrimental impact of supraoptimal root-zone temperatures by increasing the viable volume available for root growth and reducing the impact of supraoptimal root-zone temperatures on leaf A and tree growth (Ingram et al., 1986; Martin and Ingram, 1989). This argument is supported by growth medium temperature data (Fig. 1). Supraoptimal TA is a common occurrence in Florida during the midsummer months. Supraoptimal TA has a negative effect on leaf A that may not be ameliorated by growing plants in large containers (Bar-Tsur et al., 1985; Bauer, 1978; Marowitch et al., 1986). More research is needed to address the potential interaction of supraoptimal air and root-zone temperatures on photosynthetic capacity and plant growth.

In conclusion, the growth of southern magnolia generally increased with increased container volume. Growth medium temperature patterns at the center location differed as a function of container volume. The mean maximum temperature at the center location was 4.8 and $6.3 \mathrm{C}$ lower for the 57LC than for the 27 and 10LC, respectively. Thus, the time required for magnolias to attain marketable size when containers are spaced apart may be reduced by implementing production schedules that shift trees to larger container volumes earlier in the production cycle than usual or that start trees in the container volume in which they will be marketed. Our results suggest that using larger container volumes to increase carbon assimilation and tree growth may be even more important when daily maximum air temperatures are lower during late spring and early fall because low solar angles directly isolate part of the container surface.

\section{Literature Cited}

Appleton, B. and C. Whitcomb. 1983. Effects of container size and design and transplanting date on growth of tree seedlings, J. Env. Hort. 1:89-93.

Aung, L.H. 1974. Root-shoot relationships, p. 29-62. In: E.W. Carson (cd.). The plant root and its environment. The University Press of Virginia, Charlottesville, Va.

Bar-Tsur, A., J. Rudich, and B. Bravdo. 1985. High temperature effects on $\mathrm{CO}_{2}$ gas exchange in heat-tolerant and sensitive tomatoes. J. Amer. Soc. Hort. Sci. 110:582-586.

Bauer, H. 1978. Photosynthesis of ivy leaves (Hedera helix) after heat stress. Physiol. Plant 44:400-406.

Biran, I. and A. Eliassaf. 1980. The effect of container shape on the development of roots and canopy of woody plants. Scientia Hort. 12:183-193.

Bunce, J.A. 1985. Effects of day and night temperature and temperature variation on photosynthetic characteristics. Photo. Res. 6:175181.

Bunce, J.A. 1988. Nonstomatal inhibition of photosynthesis at high transpiration rates without stomatal closure in field-grown tomato. Photo. Res. 18:357-362.

Carmi, A. and D. Keller, 1978. Effects of the roots on the rate of photosynthesis in primary leaves of bean (Phaseolus vulgaris L.). Photosynthesis 12:178-184.

Carmi, A., J.D. Hesketh, W.T. Enos, and D.B. Peters. 1983. Interrelationships between shoot growth and photosynthesis, as affected by root growth restriction. Photosynthesis 17:240-245.

Cowan, I.R. 1977. Stomatal behavior and environment. Adv. Bet. Res. 4:117-228.

Cowan, I.R. and J.H. Troughton. 1971. The relative role of stomata in transpiration and assimilation. Planta 97:325-336.

Dietz, K.J. and U. Heber. 1986. Light and $\mathrm{CO}_{2}$ limitation of photosynthesis and states of the reactions regenerating ribulose-1,5-biphosphate or reducine 3-phosphoglycerate. Biochim. Biophys. Acts. 848:392-401.

Downtown, W. J., B.R. Loveys, and W.J. Grant. 1988. Stomatal closure fully accounts for the inhibition of photosynthesis by abscisic acid. New Phytol. 108:263-266. 
Flanagan, L.B. and R.L. Jefferies. 1988. Stomatal limitation of photosynthesis and reduced growth of the halophyte, Plantago maritima L., at high salinity. Plant Cell \& Env. 11:239-245.

Gilliam, C., G. Cobb, and C. Evans. 1984. Effects of nitrogen concentration and container size on growth of Pyrus calleryana 'Bradford'. J. Env. Hort. 2:53-56.

Gur, A., B. Bravdo, and J. Hepner. 1976. The influence of root temperature on apple trees. III. The effect on photosynthesis and water balance. J. Hort. Sci. 51:203-210.

Harrison, R.H. 1989. Growth and change in nutrient concentration of woody ornamental in response to supraoptimal root-zone temperatures. MS Thesis, Univ. of Florida, Gainesville.

Ingram, D.L. 1985. Modeling high temperature and exposure time interactions on Pittosporum tobira root cell membrane thermostability. J. Amer. Soc. Hort. Sci. 110:470-473.

Ingram, D.L. and C. Ramcharan. 1988. 'Grande Naine' banana and Dracaena marginata 'Tricolor' root cell membrane heat tolerance. Fruits 43:29-33.

Ingram, D. L., C. Ramcharan, and T. Nell. 1986. Response of container-grown banana, ixora, citrus, and dracaena to elevated root temperatures. HortScience 21:254-255.

Johnson, C.R. and D.L. Ingram. 1984. Pittosporum tobira response to container medium temperature. HortScience 19:524-525.

Keever, G. J., G.S. Cobb, and R.B. Reed. 1985. Effects of container dimension and volume on growth of three woody ornamental. HortScience 20:276-278.

Littell, R.C. 1989. Statistical analysis of experiments with repeated measurements. HortScience 24:37-40.

Lorenzo-Minguez, P., R. Ceulemans, R. Gabriels, I. Impens, and O. Verdonck. 1985. Response of gas exchange behavior of Schefflera arboricola to air humidity and temperature. HortScience 2O:1060-1062.

Marowitch, J. C., C. Ritcher, J. Hoddinott. 1986. The influence of plant temperature on. photosynthesis and translocation rate in bean and soybean. Can. J. Bet. 64:2337-2342.

Martin, C.A. 1990. Modeling temperature patterns in container media and acclimatization of three tree species in supraoptimal root-zone temperatures. PhD Diss., Univ. of Florida, Gainesville.
Martin, C. and D. Ingram. 1988. Temperature dynamics in black poly containers. Southern Nurserymen Assn. (SNA) Res. Conf. 33:7174.

Martin, C.A. and D.L. Ingram. 1989. Supraoptimal root-zone temperature alters growth and photosynthesis of holly and elm. J. Arbor. $15: 272-276$

Martin, C. A., H.G. Ponder, and C.H. Gilliam. 1989. Effect of irrigation rate and media on growth of Acer rubrum L. in large containers. J. Env. Hort. 7:38-40.

Mott, K.A. 1988. Do stomata respond to $\mathrm{CO}_{2}$ concentrations other than intercellular? Plant Physiol. 86:200-203.

Prinsely, R. T., K.H. Dietz, and R.C. Leegood. 1986. Regulation of photosynthetic carbon assimilation in spinach leaves after a decrease in irradiance. Biochim. Biophys. Acts 849:254-263.

Robbins, N. and D. Pharr. 1988. Effect of restricted root growth on carbohydrate metabolism and whole plant growth of Cucumis sativus L. Plant, Physiol. 87:409-413.

Ruter, J.M. and D.L. Ingram. 1990. ${ }^{14}$ Carbon-labeled photosynthate partitioning in Ilex crenata 'Rotundifola' at supraoptimal root-zone temperatures. J. Amer. Soc. Hort. Sci. 115:1008-1013.

Tenhunen, J. D., O.L. Lange, J. Gebel, W. Beyschlag, and J.A. Weber. 1984. Changes in photosynthetic capacity, carboxylation efficiency, and $\mathrm{CO}_{2}$ compensation point associated with midday stomatal closure and midday depression of net $\mathrm{CO}_{2}$ exchange of leaves of Quercus suber. Planta 162:193-203.

van den Dreissche, R. 1987. Importance of current photosynthate to new root growth in planted conifer seedlings. Can. J. For. Res. 17:776-782.

Woodrow, I.E. 1986. Control of the rate of photosynthetic carbon dioxide fixation. Biochim. Biophys. Acts. 851:181-192.

Wong, S. C., I.R. Cowan, and G.D. Farquhar. 1979. Stomatal conductance correlates with photosynthetic capacity. Nature (London), 282:424-426

Zhang, J., U. Schurr, and W.J. Davies. 1987. Control of stomatal behavior by abscisic acid which apparently originates in the roots. J. Expt. Bet. 38:1174-1181. 